\title{
Fragmentos de historia popular II. Las mujeres en la Revolución
}

Eva Salgado

La Revolución mexicana no tomó particularmente en consideración a las mujeres, ni las mujeres tuvieron en ella una participación de primer plano, aunque los improvisados y desprovistos ejércitos revolucionarios contaron con su apoyo: no sólo con el de las soldaderas, sino con el de millares de mujeres, que desde la retaguardia o desde las aldeas y las casas amenazadas mantenian el contacto con sus hombres, llevaban mensajes y procuraban alimentos y ropa a las tropas en continuo desplazamiento. ${ }^{1}$

Cuando se piensa en los episodios militares de la Revolución, la imaginación generalmente se desplaza hacia las figuras de Francisco Villa, Emiliano Zapata, Alvaro Obregón, Felipe Angeles, y tantos otros héroes que, al frente de sus tropas, contribuyeron a decidir el destino del movimiento revolucionario. Ahora bien, ¿dónde quedaron las mujeres? Todos hemos oido hablar de La Adelita, La Valentina, Jesusita la de Chihuahua, La Rielera..., personajes que, con el transcurrir del tiempo, han pasado a formar parte de una leyenda, han mezclado la ficción con la historia.

Los corridos, el cine, la novela revolucionaria, los grabados, dan cuenta de las mujeres que no se conformaron con esperar ansiosas al hombre ausente, sino que se unieron con él a la lucha por los ideales revolucionarios. Sin embargo, además de estas fuentes, algunas más objetivas que otras, el estudio acerca de la participación de la soldadera se enriquecería con testimonios de quienes las conocieron y convivieron con ellas. Este es el objetivo del presente capítulo de "Fragmentos de historia popular"; se han seleccionado testimonios incluidos en las entrevistas de historia oral del Archivo de la Palabra, que permitan un acercamiento a los siguientes aspectos: qué era una soldadera, a qué se dedicaba, cómo se convertía una mujer en soldadera, cuáles eran sus aspiraciones. Cabe señalar que la información se ha restringido casi exclusivamente a lo que acontecía en la vida de campaña.

Los juicios que a continuación se presentan son de diversas tendencias: para algunos informantes, la mujer era "el alma de la Revolución"; otros, en cambio preguntan azorados: “Mujeres?”. La tentación por incluir solamente los juicios positivos era grande; sin embargo, habría conducido a apreciaciones por demás falsas. Debemos admitir que, durante los primeros decenios de este siglo, la mujer no sólo no era vista.predominantemente como un ente secundario, siempre supeditada a las necesidades masculinas, a pesar de que demostró su interés por participar en la lucha y en los movimientos de oposición a la dictadura, utilizando los medios a su alcance para denunciar las injusticias 
cometidas, sino también contra las clases explotadas por el régimen y sus partidarios. Para prueba bastan varios botones:

Las mujeres nos servian de mucho, pues ellas nos proporcionaban la forma de comer, figúrese usted: ¿quién nos hacia las tortillas? Nada más ellas (...). Ellas no tenían más que la idea de atender a sus maridos, a sus hermanos, a sus parientes. Siempre supieron por qué luchaban y se fundaban la idea de sus hombres (...) Sí, asistian a combates, con armas y con sus parques, con sus carrilleras (...) Desde luego, eran bravisimas de carácter, se traian a sus soldados, pero más disciplinados que los de otros generales, porque ellas además nunca se excedían, no eran viciosas. Otros generales les gustaba mucho el tequilita y el -como le-llamaban ellos - "refino", o sea el alcohol puro. Ellas no tomaban y siempre estaban.ecuánimes. ${ }^{2}$

Pues, servían a los soldados, ya bien que fueran sus esposas, o que ellos tomaban..., o las que iban, vulgarmente les dicen soldaderas, acompañando a los soldados y les hacían sus comidas. ${ }^{3}$

$P$. ¿Iban mujeres acompañando a la tropa o no?

$R$. Sí, iban también, unas porque eran sus hijos, otras porque eran sus maridos y: "Que yo me quedo, y que yo me voy y... "Pues nada más hacer bola, a exponerse también a que las mataran, pues no iban a otra cosa. Las bajaban de los trenes, y no se bajaban, porque ahí iba el marido, ahí iba el hijo, y se iban al combate, porque se iban de "machetonas", arriba de los trenes, pero no porque iban a combatir; ellas iban nada más por amor a sus parientes (...) Iban arriba del tren, ahí iban haciendo cocina; ellos comiendo y las mujeres haciendo tortillas y abajo: "OOrale, viejo!" y "orale, m'hijo!"4

$P . ¿$ Había soldaderas en la tropa?

$R$. Si, naturalmente. Muchos tenian mujeres, la mayoría tenían su mujer.

$P$. ¿Qué hacía una soldadera?

$R$. Pues, las tortillas, darles de comer a los soldados.

$P$. ¿A todos?

$R$. Nomás a sus maridos.

$P$. ¿Nada más?

$R$. A sü marido. Los que no teníamos, 'teníamos que buscar. ${ }^{5}$

$P$. ¿Habia mujeres?

$R$. Sí, pues las esposas de todos, con hijos y todo.

$P$. ¿Cómo reaccionaban las mujeres durante el combate?

$R$. Tranquilamente, en algunas veces ayudaban a su esposo a cargar (...) Algunas estaban en las trincheras y había mujeres que hacían comida para sus esposos.

$P . ~ ¿ Y$ a usted quién le daba de comer?

2 Entrevista con Juan Olivera López, realizada por Eugenia Meyer, los días 23 de noviembre y 5 de diciembre de 1972, en la ciudad de México. Archivo de la Palabra del lnstituto de Investigaciones. Dr. José Luis Mora. PHO/1/28, p. 32.

"Entrevista con Jacobo Estrada, realizada por María Alba Pastor, el 31 de octubre de 1973, en Chihuahua. Chihuahua, Archivo de la Palabra, ihidem. PHO/1/121, p. 32.

4 Entrevista con José González, realizada por Ximena Sepúlveda, el 3 de julio de 1974 , en Lerdo, Durango, Archivo de la Palabra, ibidem, PHO $/ 1 / 59$, p. 21.

s Entrevista con Porfirio Adrián Díaz Diaz, realizada por María Izabel Souza, el 17 de agostode 1973, en la ciudad de México, Archivo de la Palabra, ibidem, PHO/1/96, p. 8. 
$R$. Pues ellas, ellas, las mismas mujeres nos daban comida que les quedaba a los soldados. ${ }^{6}$

"Habia una muy famosa... (se me olvidó el nombre)"

$P$. ¿Habia mujeres con ustedes, en el ejército carrancista?

$R$. Si habia, había pocas.

$P$. ¿Pero qué?, ¿tomaban las armas?

$R$. Una o dos de ellas, sí, las conocía yo, nomás que no recuerdo el nombre, pero casi todas eran las que llevaban el alimento y todo; amantes de los jefes de operaciones, mujeres de ellos mismos.

$P$. ¿Y nada más dos tomaron las armas, digamos, soldaderas?

$R$. Sí, soldaderas, sí. Habia una muy famosa (se me olvidó el nombre), hace poco se le brindó aquí un homenaje, hace algún tiempo. ${ }^{7}$

\section{"Había una... Petra Herrera"}

$P$. ¿Usted conocía a las soldaderas?

$R$. ¡Cómo no!, si anduve con una.

$P$. A ver, platíqueme.

$R$. ¡No, porque ahí está mi señora! (Risa)

(esposa del entrevistado): ¡Me voy!

R. iNo!

$P$. ¿Había muchas?

$R$. ¡No!, eran muchas que se prestaban. En Zacatecas, vea usted qué andantes palomitas, había un colegio de monjas, y las señoritas o las madres de las muchachas las cuidaban mucho; y como necesitaban casarse, muchas se fueron con villistas, y entre ellas una se fue conmigo.

$P$. ¿Qué hacian las soldaderas?

$R$. ¿Qué hacían las soldaderas? Pues, andaban a caballo, igual que uno.

$P$. ¿Peleaban?

$R$. No.

(Esposa del entrevistado): Petra Herrera.

$R$. ¡Ah! Esa era la única; había una... Petra Herrera, ésa tenia el grado de capitán y tenía mujeres; tenía un batallón como de veinticinco muchachas (eran villistas también), y era capitana Petra Herrera. $^{8}$

"Se hacian de mujeres, tanto los soldados como los jefes"

$P$. ¿Y qué nos puede hablar de las soldaderas?

$R$. ¿Mh?

$P$. Las soldaderas.

$R$. Casi con el general Villa no habia soldaderas ¿ve?, como era

- Entrevista con Rafael Mora Valdés, realizada por Eugenia Meyer, el 7 de enero de 1975, en la ciudad de México. Archivo de la Palabra, ibidem, PHO/1/103, p. 35.

7 Entrevista con Héctor Reyes Chacón, realizada por América Teresa Briseño, el 3 de mayo de 1973, en la ciudad de México, Archivo de la Palabra, ibidem, PHO/1/52, p. 3031.

- Entrevista con Luis Garcia Márquez, realizada por Maria Alba Pastor, el 6 de septiembre de 1973, en la ciudad de México, Archivo de la Palabra, ibidem, PHO/1/101, p. 9. 
toda pura gente de caballería. Pos, traían por ahí algunas mujeres, ¿verdá?, pero, pues eran, eran casualidad, porque casi la mayor parte de las tropas de Pancho Villa erañ caballeria, no admitian mujeres.

$P$. ¿Ah! ¿Y usted no vio a ninguna?

$R$. No, pues si, cuando, cuando llegábamos a los pueblos, entonces era cuando se hacían de mujeres por ái los soldados, tanto los soldados como los jefes. ${ }^{9}$

Para algunos informantes, la presencia de las soldaderas pasó desaparcibida:

$P$. ¿Hubo mujeres en el ejército villista?

$R$. No, yo no conocí, yo no conoci. ${ }^{10}$

Incitados por sus parientes femeninos, algunos excombatientes avivan sus recuerdos:

(Nuera): Platícale cómo andaban las mujeres, cómo quedaron las mujeres muertas.

$R$. No muertas...

(Nuera): Los niños, digo, los niños...

$R$. Que tenían abajo de los trenes, hacían unas cunas grandes y ahí...

(Nuera): Abajo del tren hacían una cuna y entonces ahi se metían las mujeres con los bebitos...

$R$. Y los traiban llenos de caballería.

(Nuera): Con los caballos arriba y las mujeres abajo...

$R$. Adentro en los vagones, y todos los soldados arriba.

(Nuera): Los soldados mero arriba, los caballos en medio y las mujeres abajo, mero abajo del tren con muchachitos. Dice él que una cosa fea, porque dice que cuando los trenes pegaron, las mamás, muchas mamás se murieron $(. ..){ }^{11}$

\section{"Yo conoci a cuatro, que tenían cara de hombre"}

$R$. Pues, había unas verdaderamente admirables, también por su valor. Viene a mi memoria en estos momentos, precisamente cuando la retirada de Torreón, estuvimos peleando diez días y nos derrotaron completamente las fuerzas del general Bravo y yo me retiré y como hirieron a mi caballo, pues lo dejé abandonado, se muere. Entonces me acerqué a abordar un tren que llevaba jaulas de acero, cuando pasa otro compañero y dice: “¿Qué estás haciendo?” - "Me voy a ir en este tren, ya de retirada rumbo a Durango." Bueno, pero vimos a cuatro que estaban ahí, pues yo crei que eran hombres. "¿Y qué vas a hacer con esas marotas?", le dije. "Oye, ¿a qué te refieres?" -"Pues, ¿qué no sabes? Si no son hombres, son mujeres." - ¿Cómo

\footnotetext{
- Entrevista con José Raya Rivera, realizada por María Isabel Souza, el 20 de julio de 1973, en Parral, Chihuahua, Archivo de la palabra, ibidem, PHO/1/69, p. 20.

${ }_{10}$ Entrevista con Martín Hernández Orozco, realizada por María Alba Pastor, el 29 de octubre de 1973. en Chihuahua, Chihuahua, Archivo de la Palabra, ibidem, PHO/1/119, p. 27.

"Entrevista con Severo Medina, realizada por Mary Lee Nolan, el 3 de febrero de 1973. en Brian. Texas, Archivo de la Palabra, ibidem, PHO/1/94, p. 7.
} 
que son mujeres?" - "Pues si". Yo me subi de todas maneras, porque el tren tenía que movilizarse; efectivamente eran mujeres, anduvieron peleando (...) No, ellas acompañaban a uno donde quiera; no había muchas, desde luego, no era una cosa abundante; pero sí. habia mujeres que seguian a sus familiares, una que otra iverdad?, por excepción. Pero esa vez yo conocí cuatro, que tenían càra de hombre. $^{12}$

\section{"¡Mucha soldada!, muchas"}

$P$. ¿Los acompañaban mujeres en el ejército o no?

$R$. Habia unos soldados... el que se conseguía una mujer y se quería ir con él, pues se iba.

$P$. ¿No había problema?

$R$. No, pues no había. Era cosa de ellos. Si el soldado, por ejemplo, se conocía capaz para poder llevar a otra mujer, se la llevaba. A algunas les proporcionaban caballos y otras caminaban (...) les gustaba seguir al ejército a pie, como la tropa de caballo anda despacio se iban a pie, pero algunas andaban a caballo; pero eso ya era cosa de ellos, no era cosa de los jefes. Y luego sí había mujeres que sí las reconoció el general (Villa).

$P$. ¿Se acuerda de alguna de ellas?

$R$. Habia una de Parral, una Petra Herrera. Andaba uniformada en el ejército y andaba otra, que también era de allí, una muy nuevita, una muchacha muy nueva y también uniformada; pero ésas las traían los jefes. Andaban con ellos, pero sin embargo andaban uniformadas y armadas a los combates, igual que los soldados.

$P$. ¿Combatían también las mujeres?

$R$. Sí, también.

$P$. ¿No huian a la mitad del combate?

$R$. Pues, una que otra. Como ésas ino! Las demás no, había muchas muchas mujeres, como el ejército creció mucho, pues, el ejército tan grande como era ya, pues habia mucha gente; muchas mujeres que andaban siguiendo a los soldados. Allá en los combates grandes, como en el combate de Celaya, los soldados en la linea de fuego, peleando, y el campamento de mujeres en otra parte. ; Mucha soldada, muchas! (...) Los que traían mujeres álli, el soldado que traía mujer, ipues pasaba muy buena vida!

$P$. ¿Pero solamente le háía su comida, le lavaba la ropa a su soldado o...?

$R$. ¡Nomás a su soldado! Nomás con el soldado se entendia, con el soldado de ella se entendía. ${ }^{13}$

\section{"Echando bala parejo"}

$R$. Acompañaban donde quiera a la tropa, y peleaban en, de cuando nos retiramos de Aguascalientes, el día 10 de julio, las mujeres echaban bala. Cuando ya salimos en el tren - yo herido- en el tren del general Villa, nos tirotearon hasta la estación de Chicalote, que está al norte de Aguascalientes. Y todo ese tramo las mujeres, en los 
- carros donde venían con el rifle, echando bala parejo. Y no nos hizo nada la caballería que nos quería cortar, y yo se lo atribuyo al concurso de las mujeres. ${ }^{14}$

Algunos revolucionarios dejan oír sus protestas porque, en la vida real, las soldaderas no eran: "como las películas que salen ái últimamente":

$R$. Y la División del Norte, también le platiçaré, que no es como las películas que salen ái últimamente, que traen muchas mujeres... y que hablan; no es cierto: la División del Norte, en la, en todas las poblaciones había pagadores y se les pagaba con su credencial, con el retrato del papá o de los hijos, les pagaba el sueldo que ganaban ellos en campaña. Y todos: no había ni una mujer en setenta mil hombres de la División del Norte, para movernos rápido. ${ }^{15}$

\section{"Esa Adelita, yo no la conocia"}

$P$. ¿Supo usted de algunas mujeres que participaran en la Revolución?

$R$. Pues, de esa Adelita, yo no la conocía. Y cuando entramos a Ojinaga, yo vi una mujer que andaba alli con su rifle, echando balas; pero no, no le sé decir quién era. ${ }^{16}$

Popular entre la tropa era Adelita,

la mujer que el sargento idolatraba

porque a más de ser valiente era bonita que hasta el mismo coronel la respetaba...

$P$. ¿Iban mujeres con ustedes en el ejército?

$R$. Había, claro que sí, pero en poblaciones, ¿verdad?

Pero no iban con nosotros (...) Ahora que me dice que Adelita, yo nunca conocí nada de eso, que una coronela... Yo nunca conocí nada de eso. ${ }^{17}$

\section{"Era valiente como ella sola"}

$R$. Todos los de allá; muchos de ellos tenían su virgen de Guadalupe acá, y andaban peleando y toda la cosa. Y también las soldaderas: ¡valientes mujeres aquéllas las del norte!, ¿verdad? (...) Yo quise mucho a la mujer soldadera de allá, era valiente como ella sola. A la hora de la batalla peleaban ellas parejo. ¡Uy! Peleaban, no mataban, pero ellas iban conociendo el manejo mientras sacaban de nuestros morrales en donde teníamos el parque, sacaban, para ponerlo en el máuser y en los 30-30, los tiros, y ya seguiamos nosotros tirando. Pero ellas, sí, por dondequiera morían muchas, muchas de ellas murieron en las batallas. ${ }^{18}$

14 Entrevista con Praxedes Giner Durán, realizada por María Isabel Souza, el 21 de julio de 1973, en Ciudad Camargo, Chihuahua, Archivo de la Palabra, ibidem PHO/1/75, p. 14.

${ }_{15}$ Entrevista con Rafael Sánchez Cano, realizada por Maria Alba Pastor, el 2 de noviembre de 1973, en Hidalgo del Parral, Chihuahua, Archivo de la Palabra, ibidem. $\mathrm{PHO} / 1 / 122$, p. 34.

16 Entrevista con Onéximo Coss Castillo, realizada por María Alba Pastor, el 30 de octubre de 1973, en Bachíniva, Chihuahua, Archivo de la Palabra, ibidem, PHO/1/120, p. 21.

${ }_{17}$ Entrevista con Roberto Sánchez, por América Teresa Briseño, el 13 de febrero y 13 de marzo de 1973, en la ciudad de México. Archivo de la Palabra, ibidem PHO/1/38, p. 25.

18 Entrevista con Justino López Estrada, realizada por América Teresa Briseño, el 29 de 
"Nacha Ceniceros (...) ésa era más capaz que yo y que muchos para andar a caballo"

$P$. ¿Había mujeres en el ejército?

$R$. ¡Muchas!

$P$. ¿Villistas?

$R$. De todos, de todos (...) Ordenaba Villa que cuando iba a tomarse una plaza que no fueran mujeres (...)

$P$. ¿Entonces, en combate casi no iban mujeres?

$R$. Muy pocas, muy pocas. Bueno, el enemigo sí había, pos ái en Camargo le erró, una vieja, un tiro a Villa; le mataron al soldado, ¿verdad?, y luego ya que se terminó la cosa, la mujer erró un tiro (...) Había una, Nacha Ceniceros, pero andaba en la bola; ésa era más capaz que yo y que muchos para andar a caballo (...) Sí, ésa si le mataban al caballo, agarraba del campo un animal bruto y lo ensillaba, y brincaba pa'allá y pa'acá; el caballo no le hacia nada.

$P$. ¿Y ella combatía?

$R$. Si, valientísima, alli.

$P$. ¿Tenía rifle y todo?

$R$. Todo. Y un hijo andaba con ella, ya jovencito, de unos quince años.

$P$. ¿Y ella de dónde era?

$R$. De aquí, de Villa Matamoros, muy bonita, parecía muñeca.

$P$. ¿Y iba su ésposo también?

$R$. No, el esposo estaba como divorciado, estaban enojados, alli vivía, se llamaba Lauro Ruiz (...)

$P$. ¿Dónde se quedaban las mujeres cuando había algún combate?

$R$. En la retaguardia (...) La parte de atrás, donde no había combate. Bueno, combatían cuando... cuando nos pegaban por detrás, ¿verdad?, que luego llegaba, les llegaba así un enemigo o nos cortaban, que no viéramos, y nos venían y nos pègaban. ${ }^{19}$

\section{"Ora, como ustedes así, las muchachas llegaban con su pistola"}

$P$. ¿Y en la lucha había mujeres?

$R$. ¿Eh?

$P$. ¿Peleaban las mujeres?

$R$. También. ¡Uh! Ora, como ustedes asi, las muchachas llegaban con su pistola asi debajo: "¡Andale!" ¡No!: Los sacudían asi, como ahora los pacíficos: "¡Andale!, apúrate, ya vienen” y se adelantaban las mujeres, pues nosotros veníamos como hasta San Pedro, y aquí ya se adelantaban porque eran también muy atrevidas; habia mujeres de veras, que eran de verdad, icaramba!, si. ${ }^{20}$

\section{"Las soldaderas fueron el alma de los soldados"}

$P$. ¿Qué me puede hablar de las soldaderas?

$R$. Pues, los soldados y aun el pueblo civil deben considerarlas sa-

. marzo y 3 de abril de 1973, en la ciudad de México. Archivo de la Palabra, ibidem $\mathrm{PHO} / 1 / 49$, p. 5.

${ }_{19}$ Entrevista con José Reyes, realizada por María Isabel Souza, el Io. de julio de 1974, en Parral, Chihuahua, Archivo de la Palabra, ibidem, PHO/1/158, p. 44-46.

${ }^{20}$ Entrevista con Pascual Nieto, realizada por Maria Alba Pastor, el 28 de enero de 1975 , en la ciudad de México, Archivo de la Palabra, ibidem, PHO/1/142, p. 3. 
gradas a las soldaderas. Fueron el alma, si, las soldaderas fueron el alma de los soldados, las que en los cuarteles, campamentos y en los combates, exponiendo la vida, hambrientos, venciendo lo imposible, ellas llegaban con su soldado llevándole atole, tacos, tortillas con chile, tortillas tostadas y maíz, agua, etcétera. Lo que más llevaban era carne cruda o asada y pedazos de piloncillo. La soldadera es valiente, fiel y resignada, que en los momentos más críticos, desafiando el peligro ahí estaba la soldadera dándole ánimo y agua a su soldado. Esta fue y será la mujer incomparable que se le da el nombre de soldadera.

$P$. ¿Ellas combatían también?

$R$. Algunas, no todas, pero si se llegó a mencionar de una coronela y otras mujeres más que portaban rifles, pistolas y entraban a combates. Recuerdo de una mujer de un sargento, en el combate de Aguascalientes, estando con su sargento en la línea de fuego, se lo mataron y ella cogió el máuser de su marido y siguió combatiendo valientemente.

$P$. ¿En dónde las vio?

$R$. Con nosotros en distintas ocasiones, en muchísimas.

$P$. ¿Pero no recuerda en qué batallas?

$R$. En algunas partes, sí, en la Cuesta de Sayula, Torreón, Aguascalientes, en más àgarres, que es imposible retener en la memoria de quienes en momentos tan apremiantes las veiamos.

$P$. ¿Iban sus niños también?

$R$. No, sus niños los tenían en los carros caja de los trenes, que ocupaban los batallones a donde pertenecian sus maridos, por debajo del carro hay unas varillas gruesas, en donde los soldados hacian con tablitas y alambres, muy bien asegurados, una especie de camarotes donde viajaban con su soldadera y sus hijos. Se caminaba muy a gusto, pero sumamente peligroso. Los soldados y clases asi viajaban, seguramente por no querer ir revueltos con los demás y ya sea dentro de los carros o en los techos se acomodaban.

$P$. ¿A qué se dedicaban especialmente ellas?

$R$. Como toda mujer casada que atiende su hogar, así es que a lo que se dedican las mujeres de los soldados, nomás con una diferencia grandísima: que las soldaderas lavan, planchan, remiendan, hacen tortillas, hacen las comidas, sin nada de comodidades y mucho menos que dispongan de tener los medios para hacer su trabajo doméstico, pero lo más de tomarles muy en cuenta, es que exponen su vida por su soldado.

$P$. ¿A todos les hacían la comida?

$R$. No, a todos no, a sus maridos. Y los que éramos solos comíamos con unas señoras que se dedicaban a vender comida, a éstas les llamábamos madres; también habían señoras que con autorización de su marido asistían a dos o tres compañeros, siempre era de costumbre que la provisión siempre se las dábamos a quienes nos asistían. Así es que en lo general todos comíamos. Habían también que de los solos, solteros, se juntaban cuatro o más, se formaban haciéndose sus comidas. ${ }^{21}$

21 Entrevista con Francisco Ruiz Moreno, realizada por Maria Isabel Souza, el 17 de julio de 1973, en Ciudad Juárez, Chihuahua, Archivo de la Palabra, ibidem, PHO/1/66, p. 26. 
Para cerrar este capitulo, se incluye un testimonio que comprueba que el valor de las mujeres no sólo se demostró en el campo de batalla:

$R$. Conoci a doña Juana $B$. Gutiérrez de Mendoza que había publicado un periódico que se llamaba Vésper, que había estado presa en Belén seis veces o siete, que había estado con los Flores-Magón en El Paso y en San Antonio.

$P$. ¿Y cómo la conoció usted?

$R$. La primera vez, incidentalmente, en una imprenta que estaba en Cuautla; pero la traté más cuando estuvo en México, al triunfo del Plan de Agua Prieta.

$P$. ¿Y qué tipo de mujer era ésta?

$R$. Una mujer como de unos... cuando la conocí tendria unos 38 a 40 años (...) Muy capaz, de un pensamiento muy rápido. Tenía una cultura, pues, lo que, la cultura que daba el medio, no muy rica. Por ella conoci a Villarreal, y conocí a otras gentes... a Sarabia (...)

Voy a hacerle un retrato de ella, para que la conozca: era de Santiago Papasquiaro, Durango. Ahi creció hasta la época en que se casó. De ahí se pasó a Durango, con su marido (...) Ya en México - se vinieron de Durango a México- empezó a publicar un periódico que se llamó Vésper(...) Ella era la directora, la impresora y la escritora del periódico. ${ }^{22}$

A lo largo de estos fragmentos el lector se puede percatar cómo las mujeres fueron algo más que una "Adelita, popular entre la tropa", o una "Rielera con su Juan". En el campo de batalla, por ejemplo, se encargaron de proporcionar al hombre alimento y apoyo moral, sin lo cual la lucha habria sido punto menos que imposible. Es justo, pues, que, a la par de los grandes héroes masculinos, rindamos homenaje a aquellas mujeres que colaboraron para lograr el cambio.

Es de hacer notar, sin embargo, que la mujer en nuestro país, "a diferencia de sus compañeras en Europa y Estados Unidos, no luchó por reivindicaciones específicas para ella como sexo marginal dentro de la sociedad, sino que estuvo al lado del hombre por mejorar la situación en general. No pedía aún el voto femenino, pero lo hizo en la primera oportunidad que se le brindó, y ésta fue en Yucatán, a raiz del Primer Congreso Feminista". ${ }^{23}$ Este tuvo lugar en Yucatán, en 1916, y fue convocado por Salvador Alvarado, a la sazón gobernador de dicho estado.

Un año más tarde, al ser promulgada la Constitución de 1917, que retomó parte de los planteamientos que habian llevado al pueblo a la lucha, quedaron plasmadas algunas conquistas para la población femenina. Por ejemplo, en el capítulo referente a los derechos individuales y a la igualdad juridica, se consiguió la igualdad de la mujer ${ }^{24}$ Aunque incipientes, estos logros coronaron en parte a los invaluables esfuerzos de las mujeres en la Revolución.

22 Entrevista con Luis Vargas Rea, realizada por Eugenia Meyer y Beatriz Arroyo, los dias 29 de agosto y 4,17 y 30 de septiembre de 1975, en la ciudad de México. Archivo de la Palabra, ibidem, $\mathrm{PHO} / 1 / 164$, p. 32 y 51.

${ }^{23}$ Ana Lau, Conciencia y acción de lucha. (Aproximación a una historia del movimiento feminista en México 1970-1976), tesis, UNAM, Facultad de Filosofia y Letras, México, 1983 , p. 89.

${ }^{24}$ Cf. ibidem, p. 94-95. 